\title{
Inflation, Real Interest Rates, and the Bond Market: A Study of UK Nominal and Index-Linked Government Bond Prices
}

\section{Citation}

Barr, David F., and John Y. Campbell. 1997. Inflation, real interest rates, and the bond market: a study of UK nominal and index-linked government bond prices. Journal of Monetary Economics 39, no. 3: 361-383.

\section{Published Version}

http://dx.doi.org/10.1016/S0304-3932(97)00027-5

\section{Permanent link}

http://nrs.harvard.edu/urn-3:HUL.InstRepos:3163261

\section{Terms of Use}

This article was downloaded from Harvard University's DASH repository, and is made available under the terms and conditions applicable to Other Posted Material, as set forth at http:// nrs.harvard.edu/urn-3:HUL.InstRepos:dash.current.terms-of-use\#LAA

\section{Share Your Story}

The Harvard community has made this article openly available.

Please share how this access benefits you. Submit a story.

\section{Accessibility}


INFLATION, REAL INTEREST RATES, AND THE BOND MARKET: A STUDY OF UK NOMINAL AND INDEX-LINKED GOVERNMENT BOND PRICES

David G. Barr

John Y. Campbell

Working Paper 5821

\section{NATIONAL BUREAU OF ECONOMIC RESEARCH 1050 Massachusetts Avenue \\ Cambridge, MA 02138 \\ November 1996}

The authors are grateful to seminar participants at the Centre for Economic Performance, LSE, and the NBER for helpful comments. Campbell acknowledges the financial support of the National Science Foundation. This paper is part of NBER's research programs in Asset Pricing and Monetary Economics. Any opinions expressed are those of the authors and not those of the National Bureau of Economic Research.

(C) 1996 by David G. Barr and John Y. Campbell. All rights reserved. Short sections of text, not to exceed two paragraphs, may be quoted without explicit permission provided that full credit, including $($ notice, is given to the source. 
INFLATION, REAL INTEREST RATES,

AND THE BOND MARKET: A STUDY

OF UK NOMINAL AND INDEX-LINKED

GOVERNMENT BOND PRICES

David G. Barr and John Y. Campbell

NBER Working Paper 5821

November 1996

JEL Nos. E31, E43

Asset Pricing and Monetary Economics

\section{ABSTRACT}

This paper estimates expected future real interest rates and inflation rates from observed prices of UK government nominal and index-linked bonds. The estimation method takes account of imperfections in the indexation of UK index-linked bonds. It assumes that expected log returns on all bonds are equal, and that expected real interest rates and inflation follow simple time-series processes whose parameters can be estimated from the cross-section of bond prices. The extracted inflation expectations forecast actual future inflation more accurately than nominal yields do. The estimated real interest rate is highly variable at short horizons, but comparatively stable at long horizons. Changes in real rates and expected inflation are strongly negatively correlated at short horizons, but not at long horizons.

David G. Barr

Center for Empirical Research in Finance

Brunel University

Uxbridge, Middlesex UB8 3PH

UNITED KINGDOM

david.barr@brunel.ac.uk
John Y. Campbell

Department of Economics

Harvard University

Cambridge, MA 02138

and NBER

john_campbell@harvard.edu 


\section{Introduction}

The prices of assets traded by forward-looking agents offer a rich source of information about the expected future. Financial markets summarise the disparate and largely unobservable expectations of asset holders and reveal them in the coded form of observable prices. The challenge to economists is to break this code by modelling the relationship between individuals' expectations and market prices. In this paper we use a simple asset pricing model to convert the prices of nominal and index-linked UK government bonds into implied expectations of future real interest rates and inflation.

Implied market expectations are useful in many ways. Investors can use them to identify the points at which their own expectations diverge from the market consensus, adjusting the balance of their portfolios to take advantage of what they may regard as the market's errors. There is a similar role for market expectations in public-sector debt management, where the government may wish to minimise its funding costs.

Another important application is to monetary policy. Information about inflation expectations offers the monetary authorities a measure of the credibility of their commitment to low inflation, and may be used to inform their decisions about the setting of short-term interest rates. The nominal yield curve alone cannot be used for this. For example, an increase in nominal yields may be due to an increase in expected inflation, in which case policy should be tightened; but it may also be due to an increase in real interest rates driven by real factors, in which case tighter monetary policy may be entirely inappropriate.

To the casual observer the daily activities of government bond markets can be summarized by the 'yield curve'. The only real data to emerge from the markets, however, are in the form of bond prices. There are many methods, of varying degrees of sophistication, that may be used to convert these prices into a curve. ${ }^{3}$ Similarly, there are many ways of drawing inferences about agents' expectations from the estimated curves. Our approach is to perform these two exercises simultaneously. We use simple time-series models to represent agents' expectations, and obtain bond-price equations in which the effects of changing expectations are intuitive and easily estimated.

Once we have estimated market expectations of real interest rates and in-

\footnotetext{
${ }^{3} \mathrm{~A}$ useful review of estimation methods is provided by Deacon and Derry (1994b).
} 
flation, we study their properties over the period January 1985 through October 1994. We describe the risk and return characteristics of real and nominal bonds-important information for investors making portfolio decisions-and the ability of the bond market to forecast future inflation-important information for policymakers formulating monetary policy.

The organisation of the paper is as follows. The next section briefly explains why the task of extracting implied real interest rates from UK indexlinked bond prices is not as simple as it may seem: Index-linked bonds have significant indexation lags, and so they are not pure real bonds. To handle this problem, in Section 3 we lay out a general framework that relates nominal and index-linked bond prices to expected future inflation rates and bond returns. We then impose the log pure expectations hypothesis of the term structure to obtain a bond pricing model that is suitable for estimation. Section 4 discusses our data and econometric methodology, summarizes the recent history of nominal and real interest rates in the UK, and describes the risk and return characteristics of real and nominal bonds in our sample period. Section 5 studies the ability of the bond market to forecast future inflation, and tests the expectations hypothesis as applied to the nominal, real, and expected-inflation term structures. Section 6 concludes. 


\section{Indexation lags in UK index-linked bonds}

Economists seek to construct yield curves from real bonds in order to measure the term structure of real interest rates. Unfortunately, UK index-linked bonds are not pure real bonds. A perfectly indexed bond would pay a nominal coupon equal to the coupon rate announced at the time of issue multiplied by the proportionate increase in the general price index between the issue date and the time of payment. UK index-linked bonds, however, pay nominal coupons equal to the coupon rate announced at the time of issue multiplied by the proportionate increase in the price index from a 'reference level' dated eight months before the bond's issue date to a date eight months before the coupon payment occurs. The same indexation lag applies to the repayment of principal. Thus nominal payments on UK index-linked bonds are left unprotected against inflation occurring in the last eight months before the payments are made. ${ }^{4}$

This feature of index-linked bonds creates technical difficulties in extracting implied real interest rates from index-linked bond prices. Observed changes in the price of an index-linked bond may reflect changes in inflation expectations, albeit with a sensitivity well below that of a purely nominal bond (see Barr and Pesaran (1995)).

It is common practice to calculate the yield to maturity on an indexlinked bond conditional on a profile of inflation throughout its remaining life. Quoted index-linked yields typically assume a constant 5 per cent inflation rate and are presented as a 'real' rate. This creates a temptation to subtract this real rate from the nominal yield on a nominal, or conventional, bond of equivalent maturity (or duration) to generate a figure for average expected inflation over the remaining life of the bonds. The potential inconsistency between the derived inflation profile and that assumed at the outset is obvious. This conflict can, however, be corrected by an iterative process whereby the generated expected inflation is used to recompute the real yield on the index-linked bonds, from which a new figure for inflation can be obtained, and so on. This approach, which originates in papers by Arak and Kreicher (1985) and Woodward (1988, 1990), generates 'break-even inflation rates', so called because these are the rates that equate the yields

\footnotetext{
${ }^{4}$ See Bootle (1991) for a description of institutional features of the UK index-linked bond market.
} 
on conventional and indexed bonds.

The break-even method suffers from two problems. First, it does not generate a complete term structure of inflation, since it can be applied only to those maturities where there are equivalent pairs of real and nominal bonds. Recent research at the Bank of England has attempted to address this problem (Deacon and Derry (1994a)).

Second, the break-even method takes no account of risk or liquidity premia on real or nominal bonds. This problem is hard to handle without specifying a complete equilibrium model of the term structure such as the Cox, Ingersoll, and Ross (1985) model used by Brown and Schaefer (1994) in a study of the index-linked bond market. Brown and Schaefer estimate a real yield curve allowing for real term premia, but do not look at nominal bonds and therefore do not model inflation risk premia. They also assume that UK index-linked bonds are perfectly indexed. In future work we plan to fit an equilibrium model of both real interest rates and inflation to UK nominal and index-linked bond prices, but in this paper we follow most of the literature and assume that risk premia on all bonds are zero. 


\section{A pricing model for nominal and index- linked bonds}

In this section we develop a framework relating the prices of government bonds to expected future $\log$ real returns and inflation rates. We then use a specific model of expected bond returns, the log pure expectations hypothesis, to derive an empirically implementable bond pricing model.

\section{A general equation for bond prices}

We consider a claim to a single real payment to be made at time $t+n$. We write the $\log$ of the real payment as $v_{t+n}$, the log real price of the claim at time $t$ as $p_{t}$, and the $\log$ real return on the claim from $t$ to $t+1$ as $r_{t+1}$. Log price and $\log$ return are related by

$$
r_{t+1}=p_{t+1}-p_{t}
$$

Inverting this equation, and taking expectations conditional on information at time $t$, gives a first-order difference equation which can be solved forward to time $t+n$ to give

$$
p_{t}=-\sum_{s=1}^{n} E_{t} r_{t+s}+E_{t} v_{t+n} .
$$

This equation relates the log price of the claim at time $t$ to expected future log returns and the expected future real payment on the claim. It applies directly to zero-coupon bonds, while for coupon-bearing bonds one can calculate the prices for each coupon payment and the repayment of principal, and then add up across payments.

Equation (2) illustrates two problems that must be overcome before any empirical analysis can proceed. First, asset prices depend on expected values of $v$ and $r$, for which we have no data. We deal with this by assuming that both variables follow simple time-series processes. Second, the expectations may be asset-specific if the dividend and return processes are unique to each asset. Since this generates more coefficients than can be separately identified, we assume that there are common factors that drive the relevant movements in expectations. 


\section{Real values of nominal and index-linked payments}

In contrast to equities, real payments on bonds are driven by a single common factor, inflation. The precise way in which the real payment depends on inflation is determined by the extent to which the bond is indexed. This distinction between bonds requires some new notation; we denote claims to individual nominal payments by a subscript $j=1, \ldots, J$, and claims to individual index-linked payments by a subscript $i=1, \ldots, I$. For simplicity we normalize the declared bond payments to one, so the log of the declared bond payment is zero.

In the case of nominal bonds, since there is no indexation, the real payment is the nominal payment deflated by the general price index. Working in logs, and writing $z$ for the log price index, we have

$$
v_{j, t+n}=-z_{t+n}
$$

since the declared nominal payment has log zero.

For index-linked bonds, we define an indexation lag parameter, $l$, which is 8 months for UK government index-linked bonds. The log nominal payment on an index-linked bond is the log declared payment adjusted for the difference between the log price level $l$ months before payment, $z_{t+n-l}$, and a reference $\log$ price level $\bar{z}_{i}$ which is specific to each particular bond and is determined before the bond is issued. The real payment is again the nominal payment deflated by the general price index:

$$
v_{i, t+n}=\left(z_{t+n-l}-\bar{z}_{i}\right)-z_{t+n}=-\bar{z}_{i}-\sum_{s=1}^{l} \pi_{t+n+1-s},
$$

where $\pi_{t}=z_{t}-z_{t-1}$ is inflation from time $t-1$ to $t$. Hence whenever indexation is imperfect $(l>0)$, the real value of the payment depends on inflation during the period of the indexation lag.

Real prices of nominal and index-linked zero-coupon bonds

Substituting (3) into (2), the real price of a nominal payment becomes

$$
p_{j n t}=-z_{t}-E_{t} \sum_{s=1}^{n} r_{j, t+s}-E_{t} \sum_{s=1}^{n} \pi_{t+n+1-s},
$$


while substituting (4) into (2) the real price of an index-linked payment is

$$
p_{\text {int }}=-\bar{z}_{i}-E_{t} \sum_{s=1}^{n} r_{i, t+s}-E_{t} \sum_{s=1}^{l} \pi_{t+n+1-s} .
$$

When there is an indexation lag $(l>0)$, the last $l$ months of inflation affect the real value of the bond payment. If $l<n$ only expected inflation is relevant whereas if $l>n$ some of the last $l$ months of inflation has already occurred at time $t$. Equation (6) gives the same price as equation (5) if we set the indexation lag equal to the length of time since the reference price index was set.

\section{Term premia and the inflation risk premium}

Equations (5) and (6) incorporate expected returns that may be assetspecific. Since this gives rise to more coefficients than can be identified, we assume that expected log returns on nominal and index-linked bonds of all maturities equal the one-period interest rate. The assumption that expected long-term bond returns are equal to the short-term interest rate is known as the log pure expectations hypothesis, while the assumption that expected nominal bond returns equal expected real bond returns is an assumption that the inflation risk premium is zero. In the conclusion we discuss alternative assumptions that we plan to apply in future work.

\section{Expectations processes for inflation and returns}

In order to obtain equations suitable for estimation we have to replace all of the expected future values in equations (5) and (6) by functions of information available at time $t$. To do this we assume that $\log$ expected inflation follows a trend-stationary $\mathrm{AR}(1)$ process:

$$
E_{t} \pi_{t+s}=g_{0, \pi}+g_{1, \pi}(s-1)+g_{2, \pi} \phi_{\pi}^{s-1} .
$$

Similarly, we assume that the expected real interest rate, which equals the expected real return on any bond of any maturity, also follows a trendstationary $\mathrm{AR}(1)$ process:

$$
E_{t} r_{t+s}=g_{0, r}+g_{1, r}(s-1)+g_{2, r} \phi_{r}^{s-1} .
$$

At time $t$ there are four parameters to be estimated for each process: $g_{0}, g_{1}$, $g_{2}$ and the adjustment parameter $\phi$. 
In principle, one might expect the real interest rate and inflation processes to be stationary around a fixed mean rather than a trend; this would imply $g_{1}=0$. However we found that in some periods the real or inflation term structures have a significant slope even at very long horizons. This causes numerical problems for a model with $g_{1}=0$, since such a model can fit the data only by setting $\phi$ extremely close to (but not equal to) one. Accordingly our general specification is the one given in equations (7) and (8).

\section{Implied nominal prices of nominal and index-linked zero-coupon bonds}

The expectations terms in equation (5) can be replaced by repeated substitution from equations (7) and (8). We can add the current log price index to get the $\log$ nominal price of a claim to a log-zero nominal payment:

$$
\begin{aligned}
p_{j n t}^{n o m}= & -n\left(g_{0, r}+g_{0, \pi}\right)-\left(g_{1, r}+g_{1, \pi}\right)\left(\frac{n(n-1)}{2}\right) \\
& -g_{2, r}\left(\frac{1-\phi_{r}^{n}}{1-\phi_{r}}\right)-g_{2, \pi}\left(\frac{1-\phi_{\pi}^{n}}{1-\phi_{\pi}}\right) .
\end{aligned}
$$

The same process can be applied to equation (6) to yield a pair of equations for the nominal prices of claims to index-linked payments (again normalized to have $\log$ zero). For payments that are of a sufficiently long maturity that their nominal value has still to be determined, i.e. for $n>l$,

$$
\begin{aligned}
p_{\text {int }}^{\text {nom }}=z_{t}-\bar{z}_{i} & -n g_{0, r}-l g_{0, \pi}-g_{1, r}\left(\frac{n(n-1)}{2}\right)-g_{1, \pi}\left(\frac{l(l-1)}{2}\right) \\
& -g_{2, r}\left(\frac{1-\phi_{r}^{n}}{1-\phi_{r}}\right)-g_{2, \pi} \phi_{\pi}^{n-l}\left(\frac{1-\phi_{\pi}^{l}}{1-\phi_{\pi}}\right) .
\end{aligned}
$$

For index-linked payments that have exhausted their indexation, i.e. for which $n<l$, the equation becomes

$$
\begin{aligned}
p_{i n t}^{n o m}=z_{t+n-1}-\bar{z}_{i} & -n\left(g_{0, r}+g_{0, \pi}\right)-\left(g_{1, r}+g_{1, \pi}\right)\left(\frac{n(n-1)}{2}\right) \\
& -g_{2, r}\left(\frac{1-\phi_{r}^{n}}{1-\phi_{r}}\right)-g_{2, \pi}\left(\frac{1-\phi_{\pi}^{n}}{1-\phi_{\pi}}\right) .
\end{aligned}
$$


Since indexed payments become nominal when their maturity falls below that of the indexation lag, equation (11) is identical to equation (9) for nominal bonds, except for the indexation that has already taken place by time $t$.

\section{Nominal prices of nominal and index-linked coupon-bearing bonds}

We calculate nominal prices of coupon-bearing bonds by adding up the nominal prices of their coupon payments and final repayments of principal. For a nominal bond with $\log$ coupons $c_{j}$ and nominal principal normalized to zero, we have

$$
p_{c, j n t}^{n o m}=\log \left[\sum_{s=1}^{n} \exp \left(p_{j s t}^{n o m}+c_{j}\right)+\exp \left(p_{j n t}^{n o m}\right)\right]+\epsilon_{j t} .
$$

For an index-linked bond with $\log$ declared coupon rate $c_{i}$ and $\log$ declared redemption payment normalized to zero, we have

$$
p_{c, i n t}^{n o m}=\log \left[\sum_{s=1}^{n} \exp \left(p_{i s t}^{n o m}+c_{i}\right)+\exp \left(p_{i n t}^{n o m}\right)\right]+\epsilon_{i t} .
$$

The error terms $\epsilon_{j t}$ and $\epsilon_{i t}$ represent pricing errors, since our model will not fit all observed nominal bond prices perfectly.

These equations ignore some practical issues that complicate the pricing of coupon-bearing bonds. Coupons on UK government bonds are paid at sixmonthly intervals. We assume instead that they are paid in equal instalments each month, to match the frequency of our observations. This creates a small bias because monthly payment would make each coupon more valuable, since the early payments could be reinvested. The effect of this is to bias our estimated rates up by around 30 basis points.

Another issue we ignore is the tax treatment of UK government bonds. Capital gains on these bonds are tax-exempt for nearly all holders. Coupon income is taxed at a range of different rates. For a significant proportion of holders the rate is zero, and the coupon tax rate for the marginal investor is unknown. We assume a rate of zero despite the fact that the prices of some of the bonds in our sample may be influenced by investors paying a higher rate. Thus here again we probably overstate both the value of the coupons actually received by investors and the yields available on both nominal and index-linked bonds. For a discussion of tax effects see Deacon and Derry (1994a,b) and Schaefer (1981). 
Overall, our calculated expectations of nominal and real interest rates are likely to have a small upward bias. This bias is probably fairly constant over time, however, so the movements of rates over time are likely to reflect the true movements of expectations. There is less bias in expected inflation, which is the difference between two upwardly biased interest-rate estimates. 


\section{Data and estimation}

Equations (9), (10), and (11) can be substituted into equations (12) and (13) to get estimable equations for observed bond prices. We can then use the cross-section of bond prices to estimate the parameter vector $\psi=\left(g_{0, r}, g_{1, r}\right.$, $\left.g_{2, r}, \phi_{r}, g_{0, \pi}, g_{1, \pi}, g_{2, \pi}, \phi_{\pi}\right)$. We use monthly data, treating each month's data set as a separate cross-section without imposing that parameter values are constant across months.

\section{Data}

We use end-of-month data, supplied by the Bank of England, on clean bond prices (that is, prices net of accrued interest). For each month the data on conventional bonds include all those bonds used contemporaneously by the Bank to construct its own yield curve. A number of bonds every month trade 'off the curve' as a result of the differential tax treatment of capital gains and coupon income, or of liquidity premia. The Bank's estimation procedure deals with the tax effects directly but retains the option to reduce the weight attached to bonds that nevertheless appear to be outliers: We omitted all such outliers at the start. The maximum number of conventional bonds used in any month is 46 , from a total of 81 , and the minimum is 25 , from a total of 50. On average across months, we use 36 bonds out of 67 . The proportion of bonds used each month ranges from $45 \%$ to $59 \%$, with a mean of $53 \%$. All of the available index-linked bonds are used each month; the range is 10 to 14 , with a mean of 12 . We also include one- and three-month interbank rates because the number of short-maturity (less than one year) conventional bonds and bills in the UK market is very small.

Long-maturity index-linked bonds contain little information about mediumterm real interest rates, and there were no index-linked bonds of medium maturity in the first few years after marketable index-linked bonds were introduced in 1981. Accordingly we begin our estimation in January 1985. In that month the remaining indexed maturity of the shortest index-linked bond was 2.5 years (so the actual maturity was 8 months higher at 3 years and 2 months). In all earlier months the remaining indexed maturity of the shortest index-linked bond exceeded 2.5 years, while in all later months it was less than this. Our sample period ends in October 1994, so we use 118 months of cross-sectional data. 


\section{Estimation method}

We estimate cross-sectional equations for the log nominal prices of couponbearing bonds. For each set of $n$ end-month observations the equal-weighted residual sum of squares $\epsilon^{\prime} \epsilon$ is minimized with respect to the coefficient vector $\psi$. Asymptotic standard errors, corrected for heteroskedasticity following White (1980), are calculated from the asymptotic variance-covariance matrix $\left[g^{\prime} g\left(g^{\prime} \hat{\Omega} g\right)^{-1} g^{\prime} g\right]^{-1}$ where $\epsilon$, the gradient $g=d(\epsilon) / d \psi^{\prime}$ and the estimated error-covariance matrix $\hat{\Omega}=\operatorname{diag}\left(\epsilon \epsilon^{\prime}\right)$ are evaluated at the optimum.

In some months there is insufficient information to identify both the trend and the adjustment cocfficient, and our general model gives very large estimated standard errors. These problems are apparent only when the adjustment parameter exceeds 0.996 , and in these cases we abandon the general model in favour of one in which either the trend or the AR(1) term is omitted, the selection being based on the residual sums of squares of the competing specifications. The chosen model has a residual sum of squares approximately equal to that of the general model in these months, and the change of model has little or no effect on the fitted processes since the problem only arises when alternative processes are almost impossible to distinguish.

The general model, with both trends and both adjustment coefficients, is selected in 56 out of 118 months. We omit the inflation trend in 41 months, and the real-rate trend in just one. The inflation and real adjustment terms are omitted in 16 and 2 months, respectively, and they are both dropped only twice. The trend coefficients are very small, with averages of $-0.0005 \%$ and $0.00006 \%$ for real rates and inflation respectively (at annual rates), suggesting that despite their presence the data can be characterized quite accurately by stationary AR(1) processes. The equations fit the cross-section of log bond prices with an average $R^{2}$ of 0.993 , ranging from 0.939 to 0.9996 . The average equation standard error is 0.007 , or $0.6 \%$ of the price in natural units, and it ranges from 0.004 to 0.016 .

\section{Comparison with other term structure estimates}

We use our estimated models to construct monthly fitted term structures, and time series of expected inflation and interest rates. One way to judge the plausibility of our estimates is to compare our fitted nominal term structures with alternative estimates. There may be minor discrepancies, but 
there should not be large differences in the nominal term structures fit by different methods. Figure 1 plots the zero-coupon nominal yield curve and standard-error bands for the last month of our sample, along with the Bank of England's estimated zero-coupon curve. The figure shows that despite the relative simplicity of our approach, it generates reasonable results.

Figure 1 compares two whole term structures at a particular point in time. Alternatively, we can compare particular points of the term structure across our whole sample period. Figures 2 and 3 do this for three-month and ten-year nominal interest rates. Previous researchers have had particular difficulty in modelling the short end of the UK nominal yield curve. Although Figure 2 reveals some significant discrepancies between the estimated threemonth nominal rate and the actual interbank rate, the two seem to move together reasonably well. Figure 3 shows that our estimated ten-year nominal rates are very close to, and slightly smaller than, ten-year nominal rates derived from the Bank of England's estimation of the yield curve.

\section{Average returns on nominal and real bonds}

Our estimates of nominal and real ex-ante yields can be used to construct notional excess returns for both nominal and pure real zero-coupon bonds. Table 1 shows sample means and standard deviations of these returns for bonds of 1-year, 5-year and 10-year maturities for the period 1985.1 to 1994.9, and for four sub-periods: 1985 to the stock market crash in $1987.10 ; 1987$ to sterling's entry into the European Exchange Rate Mechanism (ERM) in 1990.10; the two years of sterling's ERM membership, to 1992.8; and the post-ERM period.

The most striking finding in Table 1 is that real bonds have tended to deliver negative excess returns, while nominal bonds have delivered positive excess returns. This is true over the full sample period and most of our subperiods. Investors in nominal bonds have gained from generally declining inflation and nominal interest rates, while investors in real bonds have suffered from generally increasing real interest rates. Over our full sample period, the average difference between nominal and real bond returns is over $2.8 \%$ per year for investors in ten-year bonds.

Of course, this difference in sample average returns does not necessarily mean that there is any difference in the unconditional mean returns on these bonds. The difference in sample average returns may simply reflect 
random events - specifically, unexpected declines in inflation-in this particular period. The log pure expectations hypothesis, and the assumption that inflation risk is unpriced, imply that all bonds have the same unconditional mean returns so that unconditional mean excess returns are zero; to test this we can compare sample average returns with their standard errors, calculated from the standard deviations of excess bond returns and reported in parentheses in Table 1. The mean excess returns on nominal bonds and on 5-year and 10-year real bonds are not significantly different from zero in the sample as a whole, or in any subsample. The mean excess return on 1-year real bonds, however, is significantly less than zero for the sample as a whole, and marginally so for the first three subsamples.

\section{Variability of nominal rates, real rates, and inflation}

The right-hand side of Table 1 reports the standard deviations of monthly excess returns on real and nominal bonds. These increase with maturity for both types of bonds, but more rapidly for nominal bonds; thus the ratio of nominal-bond to real-bond standard deviations, which is surprisingly less than one at a horizon of one year, increases with maturity. For investors with short holding periods, short-maturity nominal bonds are less risky than short-maturity real bonds, but long-maturity nominal bonds are riskier than long-maturity real bonds. ${ }^{5}$

This pattern is caused by a negative short-term correlation between real interest rates and expected inflation. When the short-term real interest rate rises, short-term expected inflation tends to fall. These two components of the short-term nominal interest rate offset each other, reducing the variability of short-term nominal bond returns. At longer horizons, however, the correlation between changes in the real interest rate and changes in expected inflation is weak and has little effect on the variability of nominal bond returns.

This phenomenon can be seen in Figures 2 and 3, which decompose three-month and ten-year nominal interest rates into real-interest-rate and expected-inflation components. Since we have assumed that the inflation risk premium is zero, expected inflation is just the difference between the nom-

\footnotetext{
${ }^{5}$ Of course, for an investor with a long horizon a real bond with maturity equal to the horizon is riskless. Campbell and Shiller (1996) develop this point in detail.
} 
inal interest rate and the real interest rate. ${ }^{6}$ Figure 2 shows that short-run movements in the three-month real interest rate and three-month expected inflation are negatively correlated (changes in the real interest rate and inflation have a correlation coefficient of -0.81 ), but their longer-term cyclical movements seem to have a slight positive correlation so the levels of the series have a negligible correlation of 0.03 . Figure 3 , by contrast, shows that there is very little negative correlation between changes in ten-year real interest rates and ten-year expected inflation; the correlation of changes is only -0.08 in Figure 3, and the correlation of levels is positive at 0.27 .

We can use our estimates to decompose the variability of excess returns on nominal bonds into components attributable to inflation and real interest rates. Because we assume that the log pure expectations hypothesis holds, there is no term-premium component of the excess nominal bond return, and the real-interest-rate component is the same as the excess return on a pure real bond of the same maturity. The variance of the excess nominalbond return is the variance of the expected-inflation component, plus the variance of the real-interest-rate component, plus twice the covariance of the two components. Table 2 reports these two variance terms and the covariance term, as fractions of the total variance of nominal bond returns, for maturities of one year, five years, and ten years over our full sample period and several subsamples.

At short horizons, the table shows that both inflation expectations and real bond returns are highly variable-in fact, they are each more variable than the corresponding nominal bond returns. They are highly negatively correlated (the correlation coefficient is -0.69 for one-year bonds over the full sample), so there is a large negative covariance term which reduces the variability of nominal bond returns. At longer horizons, the real interest rate becomes less variable and less negatively correlated with inflation expectations; this leaves expected inflation as the dominant factor driving long-term

\footnotetext{
${ }^{6}$ The fitted values of real rates and expected inflation are non-linear functions of the models' parameter estimates, from which their standard errors can be calculated. At the ten-year maturity real rates are the most precise statistically, with standard errors ranging from 2 to 80 basis points, and averaging 12 basis points; for $95 \%$ of the sample they were below 25 basis points. The standard errors for ten-year expected inflation averaged 17 basis points, with a range of $2-85$ basis points; $74 \%$ were less than 25 basis points, and $98 \%$ were below 75 basis points. Thus our method delivers fairly precise estimates of long-horizon expectations.
} 
excess bond returns. These results are consistent with the standard deviations reported in Table 1 and the history shown in Figures 2 and 3. They are also consistent with results obtained by Campbell and Ammer (1993) in US data and by Barr and Pesaran (1995) in UK data.

Both Campbell and Ammer and Barr and Pesaran also find a large role for changing risk premia, which are ruled out by our assumptions that term and inflation premia are constant. In the next section we evaluate these assumptions by using our estimated real and nominal yields to forecast future inflation, and future changes in inflation and interest rates. 


\section{The information in the term structure}

If expectations are formed rationally, and if our estimated rates reflect the expectations of market participants, we should find that our rates contain some information about future movements in real interest rates and inflation.

Forecasting the level of inflation

There have, of course, been many investigations of the ability of nominal interest rates to forecast inflation. These typically require some assumption to be made about the variability of real rates in order that the expected inflation component of the nominal rates can be separately identified. For example, if real rates and term premia are assumed to be constant, nominal rates themselves equal expected inflation plus a constant. Our identification of separate processes for real rates and inflation is analogous to these identifying assumptions, but should result in better forecasts.

For the rest of this section we adopt a slightly different notation. All rates are in annualised, continuously compounded terms, and we define a multiperiod inflation rate $\pi_{n, t+n}$ to be the continuously compounded annualised rate of change of prices from time $t$ to $t+n$. We also drop the superscript notation for nominal rates; real rates will be indicated by a superscript $r$.

The basic equation, derived from Fisher (1930), is

$$
\pi_{n, t+n}=\alpha_{n}+\beta_{n}\left[y_{n t}-y_{n t}^{(r)}\right]+\epsilon_{n, t+n} .
$$

If risk premia are constant and investors have rational expectations, $\beta_{n}=1$, and the information in the yield curve can be measured by the explanatory power of the equation.

Using data on nominal and real yields we can estimate (14) directly. Alternatively, if the real yield $y_{n t}^{(r)}$ is a constant $\bar{y}_{n}^{(r)}$, then we have

$$
\pi_{n, t+n}=\alpha_{n}^{\prime}+\beta_{n} y_{n t}+\epsilon_{n, t+n}
$$

where $\alpha_{n}^{\prime}=\alpha_{n}-\bar{y}_{n}^{(r)}$. We will compare the explanatory power of (15) with that of (14) using our estimates of real yields.

The ability of the yield curve to predict inflation over a given horizon depends in part on its ability to predict inflation over future sub-periods (or 
'forward periods') of that horizon. We can derive the following forward-rate analogue of the estimated inflation equations,

$$
\pi_{n-m, t+n}=\alpha_{n, m}+\beta_{n, m}\left[f_{n-m, m, t}-f_{n-m, m, t}^{(r)}\right]+\epsilon_{n, m, t+n}
$$

where $f_{n-m, m, t}$ is the $(n-m)$-period nominal forward rate for the period starting at $(t+m)$ and ending at $(t+n), f_{n-m, m, t}^{(r)}$ is the corresponding real forward rate, and $\beta_{n, m}=1$ if expectations are rational and inflation and term premia are constant. If real forward rates are constant, then we have instead

$$
\pi_{n-m, t+n}=\alpha_{n, m}^{\prime}+\beta_{n, m} f_{n-m, m, t}+\epsilon_{n, m, t+n} .
$$

These two equations, (16) and (17), reduce to the previous pair of equations, (14) and (15), when $m=0$. We will compare their ability to forecast forward inflation rates.

Some examples of these variables are plotted in Figure 4. The figure shows actual inflation over the next year, $\pi_{12, t+12}$, the one-year inflation rate currently expected to prevail over the next year, $f_{12,0, t}-f_{12,0, t}^{(r)}$, and the oneyear inflation rate currently expected to prevail nine years forward, $f_{12,108, t}$ $f_{12,108, t}^{(r)}$. While current and nine-years-forward expected inflation generally move together, there are some interesting periods of divergence, particularly in the period around sterling's departure from the ERM in 1992.

Estimation results for equations (16) and (17), for horizons $n=3,6$, 9 , and 12 months and $m=0,3,6$, and 9 months, are given in Table 3 . The table reports regression coefficients $\beta_{n, m}$, with standard errors corrected for serial correlation and heteroskedasticity in the equation error using the methods of Hansen and Hodrick (1980) and White (1980). The table also reports $\bar{R}^{2}$ coefficients that summarize the ability of the bond market to forecast future inflation. At the horizon $n=3$ we use both the three-month interbank rate and our fitted three-month rate; the results are similar no matter which three-month rate is used.

The results at horizon $n=3$ suggest that over three months nominal interest rates and our measures of expected inflation contain the same amount of information about future inflation. The expected inflation series does, however, produce a coefficient rather closer to unity. Since there is no indexation of any payments with less than an eight month horizon, our model has no informational advantage over the simple nominal-rate equation in this 
maturity range: The ability of our model to forecast inflation at such short horizons depends crucially on the extent to which it is appropriate to extrapolate our real term structure back from eight months. That expected inflation performs as well as nominal rates would seem to qualify as a minor success.

At longer horizons $(n=6,9$, or 12$)$, expected inflation performs considerably better than nominal rates. The equation for annual inflation $(n=$ $12, m=0$ ), for example, has an $\bar{R}^{2}$ which is $30 \%$ greater when expected inflation is used, and an estimate of $\beta$ within one standard deviation of unity. The hypothesis $\beta=1$ is rejected only once for the expected inflation equation, but is rejected six times for the nominal-rate equation. The superior performance of expected inflation holds for all values of $m$ we consider.

Forecasting changes in nominal interest rates, real interest rates, and inflation

The expectations hypothesis of the term structure implies that current yields contain all of the available information about expected future changes in interest rates. A number of papers have attempted to test this hypothesis for nominal interest rates, and have produced mixed results (see, for example, Campbell (1995), Campbell and Shiller (1991), Fama and Bliss (1987), and Shiller, Campbell, and Schoenholtz (1983)). The stylised facts for US data are summarized by Campbell and Shiller (1991) as follows: "The slope of the term structure almost always gives a forecast in the wrong direction for the short-term change in the yield on [long bonds], but gives a forecast in the right direction for long-term changes in short rates". We now ask whether the same results appear in UK data, and whether the results for nominal interest rates apply to real interest rates and inflation.

Campbell and Shiller (1991) show that the expectations hypothesis of the term structure implies $\beta=1$ in the following equation for nominal rates,

$$
E_{t} y_{n-m, t+m}-y_{n t}=\alpha+\beta s_{n, m, t}
$$

where

$$
s_{n, m, t}=(m /(n-m)) S_{n, m, t}=(m /(n-m))\left(y_{n t}-y_{m t}\right) .
$$

According to the expectations hypothesis, term premia are constant. Thus if the yield spread $S_{n, m, t}$ between long- and short-term bonds is unusually high, investors must be expecting the yield on long bonds to rise; this will 
generate capital losses to offset the yield advantage of long bonds. Using McCulloch's (1990) estimates of US zero-coupon bond yields, Campbell and Shiller (1991) found a predominance of negative estimates for $\beta$ for almost all values of $n$ and $m$.

This equation applies equally to nominal and real rates and, therefore, to expected inflation. Table 4 shows the results of replicating these tests with our estimated data for yields up to a maturity of five years. The table reports $\beta$ coefficients, with standard errors corrected for serial correlation and heteroskedasticity. Two of the three estimates for $\beta$ using nominal rates are positive, in contrast to Campbell and Shiller's results, while four of the six coefficients for real rates and expected inflation are also positive. The estimate of $\beta$ for expected inflation when $(m, n)=(3,12)$ is significantly different from zero, but not from one. The coefficients for real and nominal interest rates are poorly determined, however, and neither zero nor one can be rejected as the true value. Overall, the results are imprecise but offer no evidence against the expectations hypothesis.

Campbell and Shiller (1991) also test the ability of the term structure to forecast changes in short ( $m$-period) rates over long ( $n$-period) horizons. Under the expectations hypothesis coefficient $\beta$ should be one in the following regression of short-rate changes on the yield spread:

$$
\begin{gathered}
S_{n, m, t}^{*}=\alpha+\beta S_{n, m, t}, \\
S_{n, m, t}^{*}=\sum_{i=1}^{k-1}(1-i / k)\left(y_{m, t+i m}-y_{m, t+(i-1) m}\right),
\end{gathered}
$$

where $k=n / m$, and $S^{*}$ is the spread that would be implied by the expectations hypothesis if agents had perfect foresight of future short-term interest rates.

The variables $S^{*}$ and $S$ can be defined in terms of a range of different rates, in addition to the nominal yields used by Campbell and Shiller. In the first column of Table 5 we repeat their regression using our estimated yields to construct both $S^{*}$ and $S$. The next two columns decompose both variables into estimated ex-ante real interest rates and expected inflation. Columns 4 and 5 are based on an $S^{*}$ constructed using actual ex-post inflation, and show the results of regressing this on our expected inflation spread and our nominal yield spread respectively, the latter equations replicating 
the 'inflation-change' regressions of Mishkin (1990). The table reports coefficients, standard errors corrected for serial correlation and heteroskedasticity, and $\bar{R}^{2}$ coefficients. ${ }^{7}$

The results reported in the first three columns of Table 5 support Campbell and Shiller's conclusion that the yield curve is better at forecasting longrun changes in short rates than at forecasting short-run changes in long rates. For nominal interest rates, the estimates of $\beta$ range from 0.69 to 1.02 , are reasonably well determined and lead us to reject the hypothesis that $\beta=1$ only for $n=6, m=3$. The results for real interest rates in column 2 also support the expectations hypothesis; the equations are well determined and the coefficients are all close to unity. For expected inflation too the results are supportive; here all of the coefficients are significantly different from zero, but not from one.

Columns 4 and 5 of Table 5 show that the term structure is less successful at forecasting future changes in actual (rather than expected) inflation. Both nominal interest rates and expected inflation rates perform poorly, although at longer horizons the estimates of $\beta$ are closer to one for expected inflation than for nominal interest rates. The regressions for short horizons confirm Mishkin's conclusion that "apparently, the term structure for maturities of six months or less contains almost no information about the path of future inflation".

\footnotetext{
${ }^{7}$ The serial correlation adjustment of Newey and West (1987) is used for the results in columns 4 and 5; the Hansen-Hodrick adjustment generated some negative standard errors in these regressions.
} 


\section{Conclusion}

The results reported in this paper demonstrate that a simple, transparent framework, applied uniformly across the maturity structure, can generate empirically reasonable and statistically precise estimates of yield and forward rate curves. Application of this framework to British index-linked bonds and conventional bonds produces a plausible decomposition of expected nominal rates into expected real rates and inflation. The decomposition generates significantly better inflation forecasts than can be obtained from nominal interest rates alone. Forecast equations using expected inflation fit actual inflation better and, unlike the equations based on nominal rates, are consistent with the expectations hypothesis of the term structure.

Real interest rates are highly variable at short horizons but display very little variation at long horizons; almost $80 \%$ of the movement of long-term nominal rates appears to be due to changes in expected long-term inflation. Changes in short-horizon real rates and expected inflation are negatively correlated, but the correlation decays towards zero as the horizon increases. Conversely, the levels of real rates and expected inflation exhibit positive correlation that increases with the horizon.

The theoretical framework employed here can be generalized in several ways. Most obviously, we need not confine our attention to models driven by the two simple processes employed here. We can allow more complicated processes for expected future inflation and real interest rates, and can see whether this significantly improves our ability to fit nominal and index-linked bond prices.

The principal theoretical shortcut used in this paper is our assumption that the data obey the log pure expectations hypothesis. While this is a significant oversimplification in theory, its empirical consequences are probably quite limited. In future research, however, we plan to use models of the wellknown Cox, Ingersoll, and Ross (1985) class, implemented in discrete time in the manner of Backus (1993), Campbell, Lo, and MacKinlay (1997), Chapter 11, and Sun (1992), to estimate constant or time-varying term premia simultaneously with the rest of the model. 


\section{References}

Arak, M., and L. Kreicher, 1985, The real rate of interest: inferences from the new UK index linked gilts, International Economic Review 26, 399408.

Backus, D.K., 1993, Cox-Ingersoll-Ross in discrete time, Mimeo. (New York University, New York, NY.)

Barr, D.G. and B. Pesaran, 1995, An assessment of the relative importance of real interest rates, inflation, and term premia in determining the returns on real and nominal UK bonds, working paper no. 32 (Bank of England, London.)

Bootle, R., 1991, Index linked gilts: A practical investment guide, 2nd ed. (Woodhead-Faulkner, London).

Brown, R.H. and S.M. Schaefer, 1994, The term structure of real interest rates and the Cox, Ingersoll, and Ross model, Journal of Financial Economics 35, 3-42.

Campbell, J.Y., 1995, Some lessons from the yield curve, Journal of Economic Perspectives 9(3), 129-152.

Campbell, J.Y. and J. Ammer, 1993, What moves the stock and bond markets? A variance decomposition for long-term asset returns, Journal of Finance 48, 3-37.

Campbell, J.Y., A.W. Lo, and A.C. MacKinlay, 1997, The econometrics of financial markets (Princeton University Press, Princeton, NJ).

Campbell, J.Y. and R.J. Shiller, 1991, Yield spreads and interest rate movements: A bird's eye view, Review of Economic Studies 58, 495-514.

Campbell, J.Y. and R.J. Shiller, 1996, A scorecard for indexed government debt, in: B.S. Bernanke and J. Rotemberg eds., NBER Macroeconomics Annual (MIT Press, Cambridge, MA).

Cox, J.C., J.E. Ingersoll and S.A. Ross, 1985, A theory of the term structure of interest rates, Econometrica 53, 385-408. 
Deacon, M. and A. Derry, 1994a, Deriving estimates of inflation expectations from the prices of UK government bonds, working paper no. 23 (Bank of England, London).

Deacon, M. and A. Derry, 1994b, Estimating the term structure of interest rates, working paper no. 24 (Bank of England, London).

Fama, E.F. and R. Bliss, 1987, The information in long-maturity forward rates, American Economic Review 77, 680-692.

Fisher, I., 1930, The theory of interest (Macmillan, New York, NY).

Hansen, L.P. and R.J. Hodrick, 1980, Forward exchange rates as optimal predictors of future spot rates, Journal of Political Economy 88, 829853.

McCulloch, J.H., 1990, US government term structure data, in: B. Friedman and F. Hahn eds., The handbook of monetary economics (NorthHolland, Amsterdam).

Mishkin, F.S., 1990, What does the term structure tell us about future inflation?, Journal of Monetary Economics 25, 77-95.

Schaefer, S.M., 1981, Measuring a tax-specific term structure of interest rates in the market for British government securities, Economic Journal $91,415-38$.

Shiller, R.J., J.Y. Campbell, and K.Schoenholtz, 1983, Forward rates and future policy: Interpreting the term structure of interest rates, Brookings Papers on Economic Activity 1, 173-217.

Sun, T., 1992, Real and nominal interest rates: A discrete-time model and its continuous-time limit, Review of Financial Studies 5, 581-611.

White, H., 1980, A heteroskedasticity-consistent covariance matrix estimator and direct tests for heteroskedasticity, Econometrica 48, 817-838.

Woodward, G.T., 1988, Comment: The real rate of interest: Inferences from the new UK index linked gilts, International Economic Review 29, 565-568. 
Woodward, G.T., 1990, The real thing: A dynamic profile of the term structure of real interest rates and inflation expectations in the United Kingdom, 1982 1989, Journal of Business 63, 378-398. 
Table 1:

Moments of excess returns

\begin{tabular}{|l|l|cccc|ccc|}
\hline & & \multicolumn{4}{|c|}{ Means } & \multicolumn{3}{|c|}{ Standard deviations } \\
\hline Sample & Maturity & Nominal & $($ s.e. $)$ & Real & (s.e.) & Nominal & Real & Ratio \\
\hline $85.01-$ & 1-year & 0.19 & $(0.55)$ & -2.53 & $(0.67)$ & 5.96 & 7.26 & 0.82 \\
94.10 & 5-year & 0.97 & $(2.57)$ & -1.17 & $(1.52)$ & 27.95 & 16.46 & 1.70 \\
& 10-year & 1.39 & $(4.23)$ & -1.44 & $(2.30)$ & 45.94 & 24.98 & 1.84 \\
\hline \hline $85.01-$ & 1-year & 0.37 & $(1.23)$ & -2.51 & $(1.35)$ & 7.09 & 7.77 & 0.91 \\
87.09 & 5-year & 1.46 & $(5.49)$ & -1.89 & $(2.80)$ & 31.55 & 16.09 & 1.96 \\
& 10-year & 1.73 & $(9.34)$ & -4.88 & $(4.26)$ & 53.65 & 24.49 & 2.19 \\
\hline $87.10-$ & 1-year & -1.34 & $(0.97)$ & -2.00 & $(1.09)$ & 5.80 & 6.53 & 0.89 \\
90.09 & 5-year & -4.64 & $(4.54)$ & -0.72 & $(2.70)$ & 27.23 & 16.19 & 1.68 \\
& 10-year & -7.43 & $(7.42)$ & -0.34 & $(3.94)$ & 44.54 & 23.65 & 1.88 \\
\hline $90.10-$ & 1-year & 1.02 & $(1.15)$ & -4.06 & $(1.34)$ & 5.62 & 6.56 & 0.86 \\
92.08 & 5-year & 7.56 & $(5.49)$ & -1.74 & $(3.83)$ & 26.88 & 18.75 & 1.43 \\
& 10-year & 11.15 & $(7.33)$ & -0.69 & $(5.90)$ & 35.89 & 28.91 & 1.24 \\
\hline $92.09-$ & 1-year & 1.38 & $(0.91)$ & -1.83 & $(1.67)$ & 4.56 & 8.35 & 0.55 \\
94.10 & 5-year & 2.07 & $(4.96)$ & -0.29 & $(3.19)$ & 24.81 & 15.95 & 1.56 \\
& 10-year & 4.27 & $(9.17)$ & 0.78 & $(4.90)$ & 45.85 & 24.51 & 1.87 \\
\hline
\end{tabular}


Table 2:

Variance decomposition of excess returns

\begin{tabular}{|l|l|ccc|c|}
\hline \multirow{2}{*}{ Sample } & & \multicolumn{3}{|c|}{ Proportion due to } & \\
\cline { 3 - 5 } & Maturity & Inflation & Real rates & Covariance & Correlation \\
\hline $85.01-$ & 1-year & 1.74 & 1.49 & -2.23 & -0.69 \\
& 5-year & 0.72 & 0.35 & -0.06 & -0.06 \\
& 10-year & 0.78 & 0.29 & -0.08 & -0.08 \\
\hline \hline $85.01-$ & 1-year & 1.59 & 1.20 & -1.79 & -0.65 \\
87.09 & 5-year & 0.89 & 0.26 & -0.15 & -0.15 \\
& 10-year & 0.91 & 0.20 & -0.11 & -0.13 \\
\hline $87.10-$ & 1-year & 1.68 & 1.43 & -2.11 & -0.68 \\
90.09 & 5-year & 0.65 & 0.33 & 0.02 & 0.02 \\
& 10-year & 0.57 & 0.21 & 0.22 & 0.32 \\
\hline $90.10-$ & 1-year & 0.98 & 1.24 & -1.23 & -0.55 \\
92.08 & 5-year & 0.63 & 0.51 & -0.15 & -0.13 \\
& 10-year & 0.96 & 0.73 & -0.69 & -0.41 \\
\hline $92.09-$ & 1-year & 6.21 & 4.90 & -10.11 & -0.92 \\
94.10 & 5-year & 0.58 & 0.24 & 0.18 & 0.24 \\
& 10-year & 0.58 & 0.18 & 0.24 & 0.37 \\
\hline
\end{tabular}


Table 3:

Inflation forecasting regressions

\begin{tabular}{|c|c|c|c|c|c|c|c|c|}
\hline \multirow[b]{3}{*}{$\mathrm{n}$} & \multicolumn{8}{|c|}{$\mathrm{m}$} \\
\hline & \multicolumn{4}{|c|}{ Interest rates } & \multicolumn{4}{|c|}{ Expected inflation } \\
\hline & 0 & 3 & 6 & 9 & 0 & 3 & 6 & 9 \\
\hline 3 (interbank) & 0.71 & & & & & & & \\
\hline & $\begin{array}{c}(0.22) \\
0.20\end{array}$ & - & - & - & - & - & & - \\
\hline 3 & $\begin{array}{c}0.77 \\
(0.25)\end{array}$ & - & - & - & $\begin{array}{c}1.03 \\
(0.35)\end{array}$ & - & - & - \\
\hline $\bar{R}^{2}$ & 0.21 & & - & - & 0.21 & & & \\
\hline 6 & - & $\begin{array}{c}0.28 \\
0129\end{array}$ & - & ـ & - & $\begin{array}{c}0.49 \\
(0.14)\end{array}$ & - & - \\
\hline $\bar{R}^{2}$ & & 0.10 & & & & 0.17 & & \\
\hline 9 & & 0.38 & 0.37 & & & 0.73 & 0.71 & \\
\hline & - & $(0.15)$ & $(0.14)$ & - & - & $(0.22)$ & $(0.26)$ & - \\
\hline $\bar{R}^{2}$ & & 0.15 & 0.06 & & & 0.30 & 0.14 & \\
\hline 12 & 0.57 & 0.50 & 0.45 & 0.45 & 0.81 & 0.87 & 0.79 & 0.66 \\
\hline & $(0.19)$ & $(0.21)$ & $(0.21)$ & $(0.24)$ & $(0.30)$ & $(0.27)$ & $(0.29)$ & $(0.22)$ \\
\hline $\bar{R}^{2}$ & 0.24 & 0.13 & 0.08 & 0.03 & 0.31 & 0.25 & 0.17 & 0.05 \\
\hline
\end{tabular}


Table 4:

Regressions of $y_{n-m, t+m}-y_{n t}$ on predicted change $s_{n, m, t}$

\begin{tabular}{|c|cc|cc|cc|}
\hline \multirow{5}{*}{$\mathrm{n}$} & \multicolumn{2}{|c}{$\begin{array}{c}\text { Nominal } \\
\text { rates }\end{array}$} & \multicolumn{2}{c}{$\begin{array}{c}\text { Real } \\
\text { rates }\end{array}$} & \multicolumn{2}{c|}{$\begin{array}{c}\text { Expected } \\
\text { inflation }\end{array}$} \\
\cline { 2 - 7 } & \multicolumn{6}{c|}{$\mathrm{m}$} \\
\hline 12 & 3 & 12 & 3 & 12 & 3 & 12 \\
& 0.26 & & 0.66 & & 1.37 & \\
& $(0.47)$ & - & $(0.49)$ & - & $(0.58)$ & - \\
& -0.43 & 0.96 & 0.06 & 0.25 & -0.54 & -0.07 \\
& $(1.83)$ & $(1.35)$ & $(0.75)$ & $(0.60)$ & $(1.00)$ & $(0.86)$ \\
\hline
\end{tabular}


Table 5:

Regressions of $S_{n, m, t}^{*}$ on $S_{n, m, t}$

\begin{tabular}{|c|ccc|cc|}
\hline & \multicolumn{5}{|c|}{$S^{*}: S$} \\
\cline { 2 - 6 } & \multicolumn{3}{|c}{ estimated:estimated } & \multicolumn{3}{c|}{ actual:estimated } \\
\hline \multirow{4}{*}{ n,m } & 1 & 2 & 3 & 4 & 5 \\
& nom:nom & real:real & $E(\pi): E(\pi)$ & $\pi: E(\pi)$ & $\pi:$ nom \\
\hline 6,3 & 0.69 & 0.88 & 1.19 & -1.20 & 0.36 \\
& $(0.13)$ & $(0.21)$ & $(0.38)$ & $(0.98)$ & $(1.90)$ \\
$\bar{R}^{2}$ & 0.10 & 0.13 & 0.23 & 0.01 & -0.01 \\
\hline 9,6 & & & & -0.11 & 1.29 \\
& - & - & - & $(0.73)$ & $(1.20)$ \\
$\bar{R}^{2}$ & & & & -0.01 & 0.00 \\
\hline 12,3 & 0.89 & 0.88 & 1.16 & -0.12 & 2.12 \\
& $(0.26)$ & $(0.11)$ & $(0.14)$ & $(0.71)$ & $(1.13)$ \\
$\bar{R}^{2}$ & 0.11 & 0.26 & 0.48 & -0.01 & 0.04 \\
\hline 12,6 & 0.74 & 0.92 & 1.33 & 0.63 & 3.33 \\
& $(0.38)$ & $(0.21)$ & $(0.21)$ & $(0.67)$ & $(1.14)$ \\
$\bar{R}^{2}$ & 0.04 & 0.16 & 0.36 & 0.01 & 0.14 \\
\hline 12,9 & & & & 1.21 & 2.62 \\
& - & - & - & $(0.67)$ & $(1.21)$ \\
$\bar{R}^{2}$ & & & & 0.02 & 0.05 \\
\hline 24,12 & 1.02 & 0.77 & 0.89 & 0.83 & 3.05 \\
& $(0.46)$ & $(0.30)$ & $(0.33)$ & $(0.74)$ & $(0.61)$ \\
$\bar{R}^{2}$ & 0.08 & 0.16 & 0.17 & 0.04 & 0.39 \\
\hline
\end{tabular}




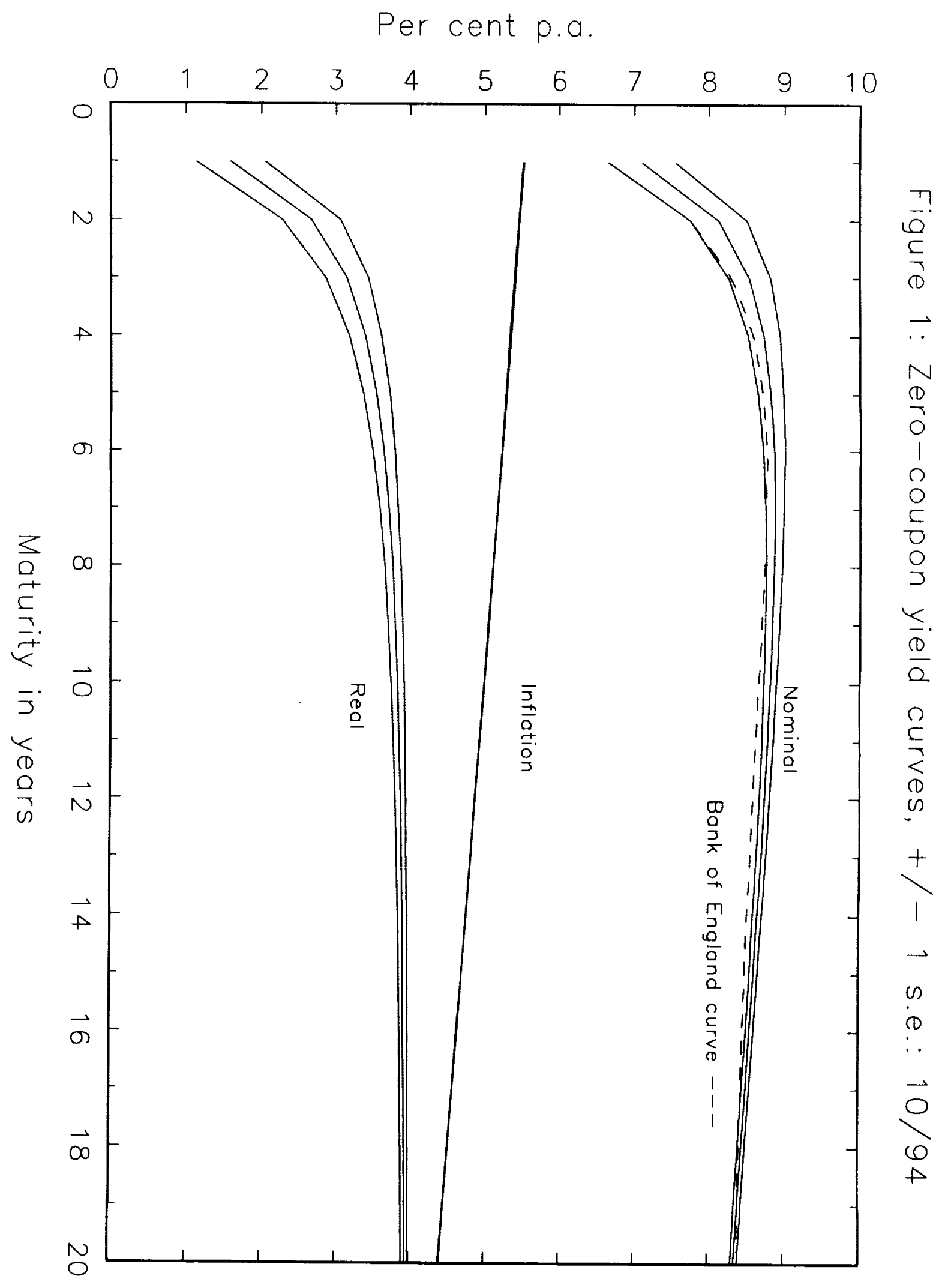


Figure 2: Estimated and interbank 3-month rates

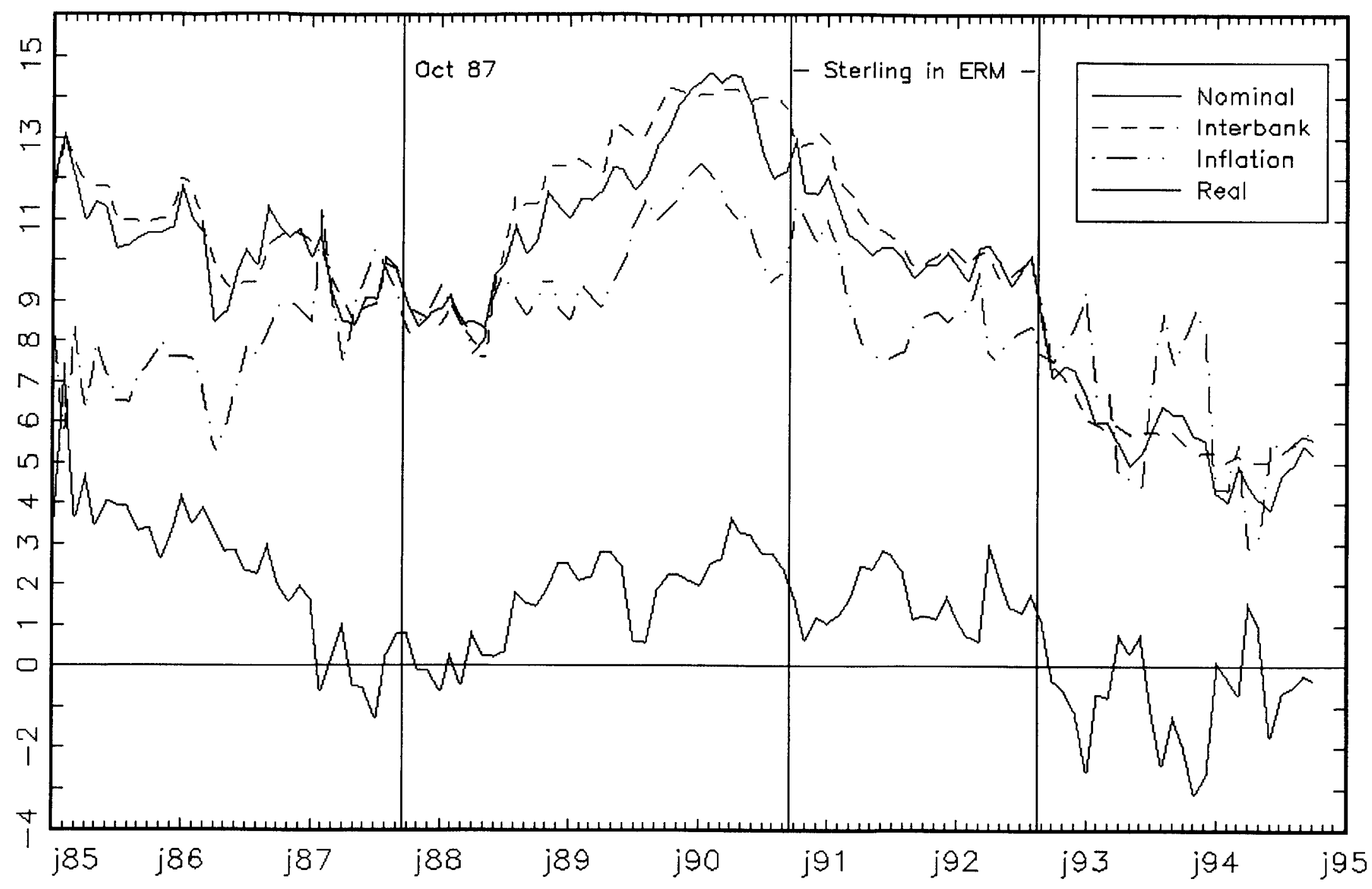


Figure 3: Estimated and BoE 10-year zero-coupon yields

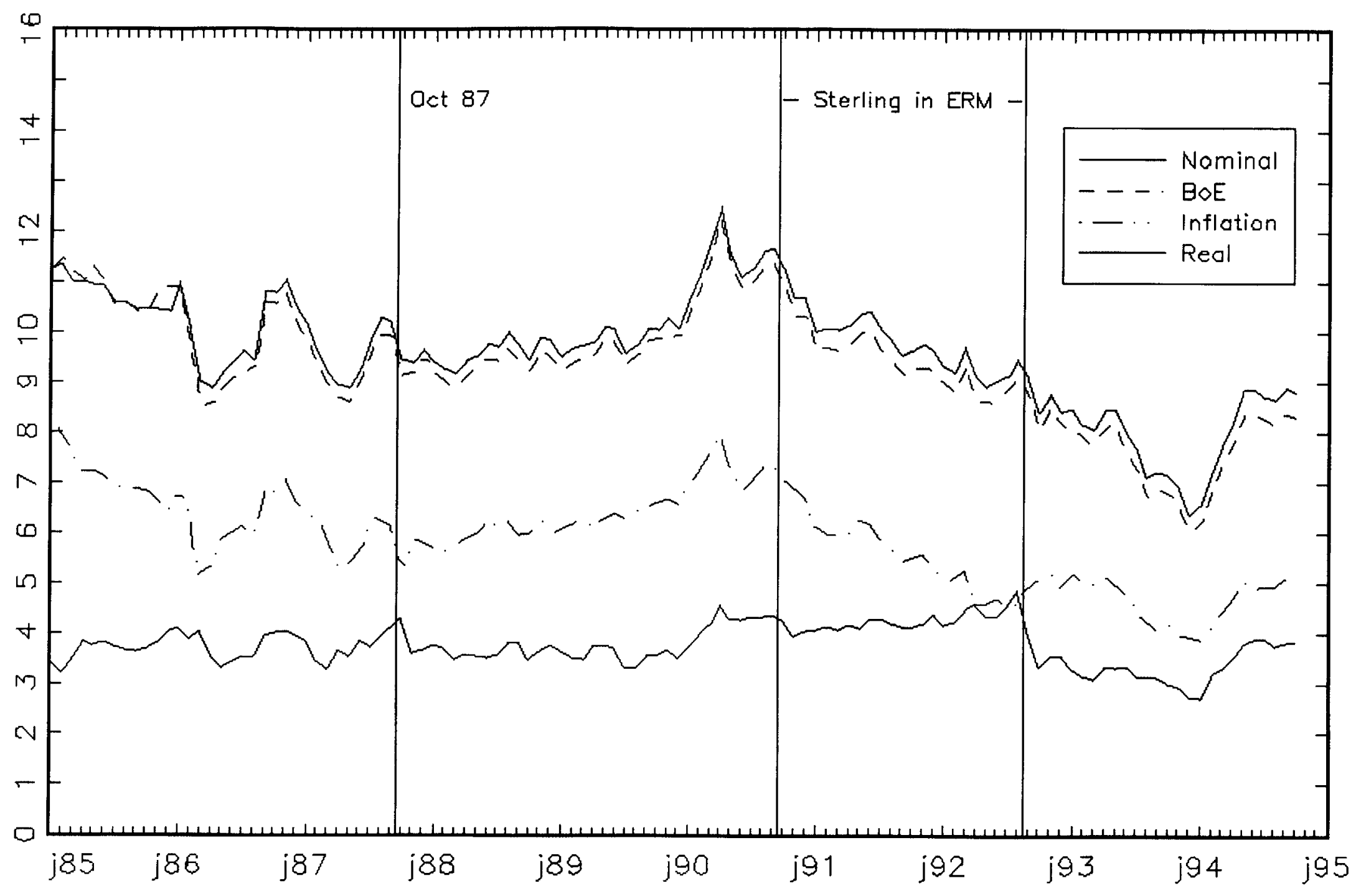


Figure 4: Expected annual inflation: current and 9yrs forward

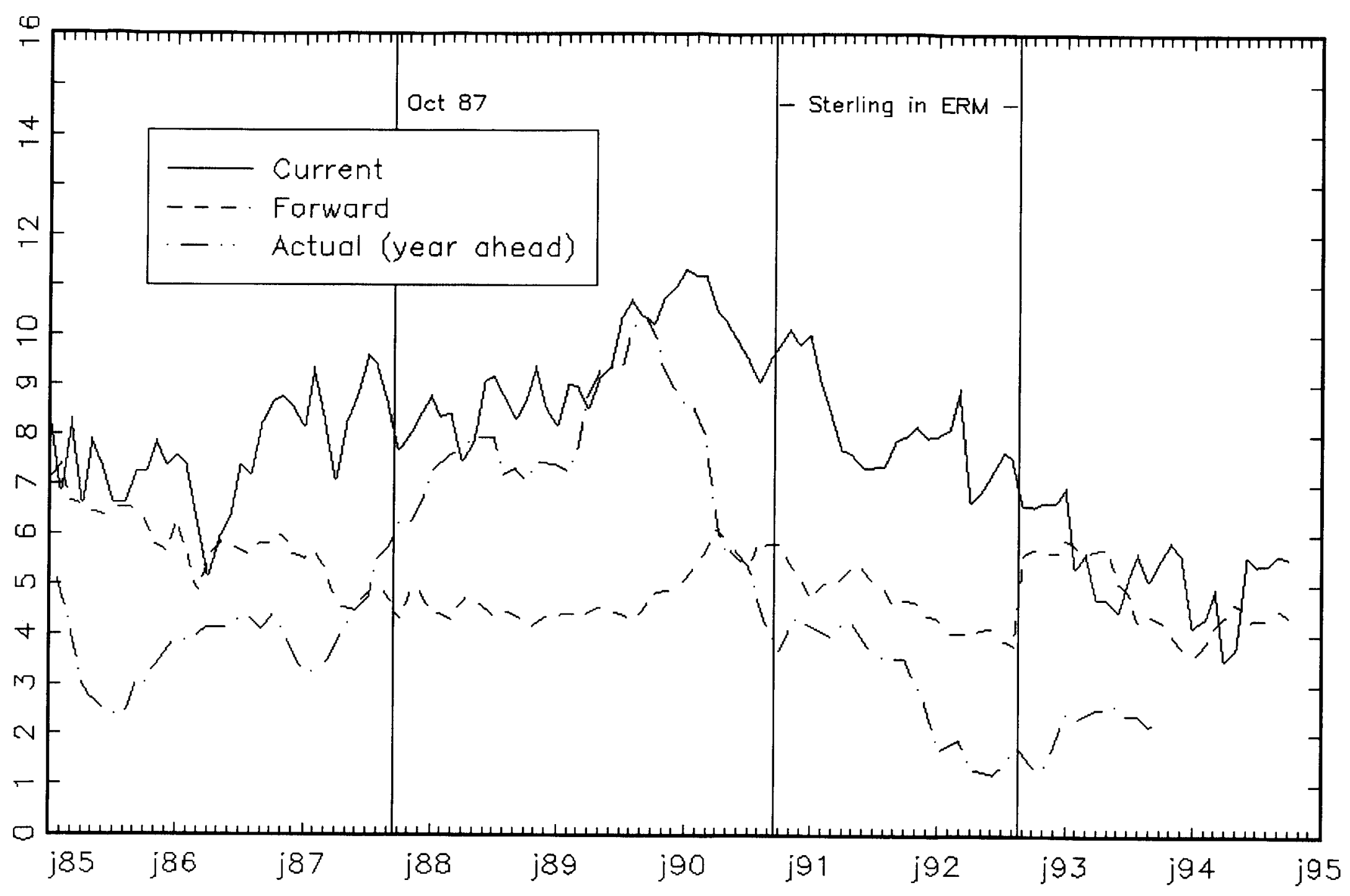

